\title{
PENGARUH PERIKLANAN ISLAMI TERHADAP KEPUTUSAN PEMBELIAN PRODUK SHAMPOO HIJAB SUNSILK CLEAN AND FRESH PADA MAHASISWI UNIVERSITAS ISLAM RIAU
}

\author{
Zulkifli $^{1}$, Boy Syamsul Bakhri ${ }^{2}$, Maysuri $^{3}$, Ficha Melina ${ }^{4}$ \\ Universitas Islam Riau ${ }^{1,2,3,4}$ \\ Email: zulkifli_rusby@fis.uir.ac.id ${ }^{1}$
}

\begin{abstract}
ABSTRAK
Tujuan penelitian untuk mengetahui pengaruh periklanan Islami terhadap keputusan pembelian Shampoo Hijab Sunsilk Clean and Fresh. Subjek penelitian ini adalah mahasiswi universitas islam riau. Sementara objek dalam penelitian ini adalah pengaruh periklanan Islami terhadap keputusan pembelian Shampoo Hijab Sunsilk Clean and Fresh. Sumber data yang digunakan dalam penelitian ini data primer dan data sekunder. Teknik pengambilan sampel digunakan dengan cara proportionate stratified random sampling, sedangkan teknik pengumpulan data yang digunakan adalah angket. Untuk menganalisis data digunakan metode deskriptif kuantitatif. Dalam menganalisis data kuantitatif digunakan analisis regresi linear sederhana dimana proses perhitungannya menggunakan SPSS for windows versi 23. Sampel penelitian ini sebanyak 96 orang. Hasil penelitian ini diketahui periklanan Islami terhadap keputusan pembelian Shampoo Hijab Sunsilk Clean and Fresh memiliki hubungan yang kuat atau tinggi, ini diketahui dari nilai koefisien korelasi sebesar 0,763. Hasil penelitian, hasil uji parsial terdapat pengaruh yang signifikan antara perikalan Islami terhadap keputusan pembelian Shampoo Hijab Sunsilk Clean and Fresh, ini diketahui dari nilai $t_{\text {hitung }}(11,452)$ lebih besar dari $t_{\text {tabel }}(1,661)$. Simpulan, terdapat pengaruh yang signifikan antara periklanan Islami terhadap keputusan pembelian shampoo hijab sunsilk clean and fresh pada Mahasiswi Universitas Islam Riau
\end{abstract}

Kata Kunci : Periklanan Islami, Keputusan Pembelian

\section{ABSTRACT}

The purpose of the research was to determine the effect of Islamic advertising on purchasing decision for Clean and Fresh Sunsilk Hijab Shampoo. The subject of this research was students of Riau Islamic University. While the object of this study was the effect of Islamic advertising on purchasing decision for Clean and Fresh Sunsilk Hijab Shampoo. The data sources used in this study were primary data and secondary data. The sampling technique used was proportional stratified random sampling, while the data collection technique used was a questionnaire. To analyze the data, quantitative descriptive method was used. In analyzing quantitative data, simple linear regression analysis was used where the calculation process used SPSS for windows version 23. The sample of this study was 96 people. The result of the research showed Islamic 
advertising on purchasing decision for Clean and Fresh Sunsilk Hijab Shampoo had a strong or high relationship, this was related to the correlation coeffisien which was 0.763. The result of the research, the result of partial test related to the significant influence between Islamic advertising on purchasing decisions for Clean and Fresh Sunsilk Hijab Shampoo, it was known from the value of tcount (11.452) which was bigger than t table (1.661). Conclusion, there was a significant effect between Islamic advertising on purchasing decisions for clean and fresh sunsilk hijab Shampoo to students of Riau Islamic University

Keywords: Islamic Advertising, Purchasing Decision

\section{PENDAHULUAN}

Perkembangan hijab di Indonesia sangatlah cepat dari tahun ke tahun. Kerudung atau hijab merupakan kata yang tidak asing di dengar oleh telinga kita saat ini, suatu kain yang berfungsi menutup aurat bagi wanita kini tengah ramai dipergunakan sebagai trend center di dunia fashion. Rambut adalah salah satu aset kecantikan yang dimiliki oleh kaum wanita karena berkaitan penting dengan rasa percaya diri. Tidak terkecuali bagi mereka yang berhijab, namun seringkali yang menggunakan hijab mengalami masalah rambut. Bagian kepala yang tertutup sepanjang hari membuat kepala berkeringat sehingga rambut menjadi lepek dan beraroma tidak segar. Salah satu produk yang sering dipakai adalah Shampoo.

Hal ini dimanfaatkan oleh para industri multinasional dan lokal untuk mengembangkan bisnisnya, salah satunya Unilever lewat Brand Shampo Sunsilk yang sangat peduli terhadap perempuan yang berhijab. Lewat varian Clean and Fresh yang menyasar wanita berhijab, Sunsilk kembali gencar melakukan strategi marketing.

PT. Unilever yang menguasai pangsa pasar memberikan dampak peningkatan mutu dari perusahaan untuk membuat banyak masyarakat yang berminat menggunakan Sunsilk, hal tersebut juga didukung hasil survey MARS-SWA sebuah majalah bisnis yang menunjukkan, di lima besar angka TOP tersebut pada Sunsilk yang menunjukkan pertumbuhan yang meningkat. Berikut ini tabel kinerja produk Shampoo seperti yang ditampilkan sebagai berikut: 
Tabel 1

Kinerja Produk Shampo

\begin{tabular}{llll}
\hline Produk & $\mathbf{2 0 1 1}$ & $\mathbf{2 0 1 2}$ & $\mathbf{2 0 1 3}$ \\
\hline Sunsilk & 26,4 & 28,7 & 29,3 \\
\hline Pantene & 22,4 & 21,2 & 26,1 \\
\hline Clear & 19,3 & 21,5 & 18,7 \\
\hline Lifeboy & 12,7 & 13,6 & 12,8 \\
\hline Rejoice & 5,7 & 5,8 & 5,3 \\
\hline Sumber: MARS-SWA & 2014 & &
\end{tabular}

Dalam penelitian ini, peneliti memilih Sunsilk Clean and Fresh karena berdasarkan pangsa pasar di Indonesia banyak yang memakai hijab sehingga dari segi penjualan di tahun 2015 Sunsilk Clean and Fresh penjualannya meningkat (www.unilever.co.id). Hal itu juga dikarenakan sejauh ini respons pasar terhadap hijab terbilang bagus. Demand-nya naik hingga $400 \%$ dibandingkan produk Sunsilk yang lainnya (www.unilever.co.id).

Iklan televisi Shampoo Sunsilk Hijab Clean and Fresh didukung dengan adanya brand amsasdore artis yang memakai style hijab masa kini yakni: Risty Tagor, juara sunsilk hijab hunt 2015 (Bella Almira, Ninda Putri, Laili, Dan Devi Handayan), dan Laudya Cynthia Bella. Shampoo Sunsilk Hijab Clean and Fresh berada di bawah naungan PT. Unilever Indonesia. Iklan shampoo ini memiliki beberapa versi, yaitu: Sunsilk Hijab Clean and Fresh versi kepala dingin hati sejuk, juara sunsilk hijab hunt 2016, dan Laudya Cynthia Bella.

Dalam penjelasan yang terjadi Antara media iklan dan simbolitas yang dipaparkan oleh media iklan televise Shampoo Sunsilk Hijab Clean and Fresh versi kepala dingin hati sejuk, juara sunsilk hijab hunt 2016, dan Laudya Cynthia Bella. Iklan shampoo pada media televise biasanya menghadirkan sosok perempuan cantik dengan rambut hitam, lebat, panjang, dan berkilau. Berbeda dengan produk Shampoo pada umunya dalam iklan Shampoo Sunsilk Hijab Clean and Fresh ini justru menghadirkan sosok perempuan yang menggunakan Hijab.

Landasan etika bisnis yang harus diperhatikan dalam periklanan adalah prinsip kesatuan, pertanggung jawaban, kehendak bebas, kebajikan, dan kebenaran. Dalam proses membuat dan menyebarkan suatu informasi iklan harus terdapat nilai keyakinan bahwa tidak ada satu aktifitas pun yang lepas dari pengawasan Allah SWT. Suatu 
informasi produk walaupun dengan cara bebas memilih kreasi penyampaiannya, tetapi dibatasi oleh pertanggungjawaban secara horizontal dan vertifikasi sekaligus. Suatu kebebasan yang tidak terkendali yang membuat suatu kebohongan pasti tidak akan membawa dampak positif walaupun dalam jangka pendek mungkin menguntungkan, demikian pula nilai kebenaran harus dijunjung tinggi untuk mempertahankan suatu tujuan luhur dari bisnis.

Jadi iklan Islami adalah bentuk komunikasi tidak langsung yang didasari pada informasi mengenai suatu produk yang bertujuan untuk mempengaruhi konsumen dan dalam penyajiannya berlandaskan pada etika periklanan Islami. Adapun kriteria mahasiswa/i Universitas Islam Riau yang menganut Agama Islam adalah dengan selalu menjunjung tinggi Agama, martabat Agama Islam dan dengan selalu mengikuti peraturan pada Universitas Islam Riau. Salah satunya adalah cara berpakaian mahasiswa/i Universitas Islam Riau yang sesuai dengan tuntunan Agama Islam dan batasan- batasannya dan bagi mahasiswa/i Universitas Islam Riau yang non-muslim dengan saling menghargai setiap aturan yang telah dibuat Universitas Islam Riau.

Fenomena pada mahasiswi Universitas Islam Riau yang sebagian sudah penulis teliti adalah sudah sebagian mahasiswi Universitas Islam Riau yang menggunakan Shampoo Hijab Sunsilk Clean And Fresh dan alasannya karena mereka Shampoo Hijab Sunsilk Clean and Fresh cocok dengan rambut mereka yang menggunakan hijab sehingga mengurangi bauk lepek dan ketombe dan ada juga yang tertarik dengan iklannya karena pada iklan Shampoo Hijab Sunsilk Clean And Fresh oleh wanita muslimah yang menggunakan hijab dan Sunsilk Hijab Sunslik Clean And Fresh setiap tahunnya menyelenggarakan model Sunsilk Hijab Hunt sehingga sangat memotivasi mereka dalam berhijab dan memakai Shampoo Hijab Sunsilk Clean And Fresh.

\section{KAJIAN TEORI}

\section{Iklan}

Dalam dunia bisnis, iklan dijelaskan oleh (Rangkuti, 2008). Iklan adalah salah satu alat komunikasi pemasaran dan alat komunikasi pemasaran lainnya adalah public relations dan promosi penjualan. Iklan juga merupakan alat, apabila alat ini dapat digunakan secara baik dan benar, ia akan menghasilkan kekuatan yang sangat dahsyat. Iklan sangat baik untuk menciptakan kesan yang sama, untuk menunjukkan perbedaan 
antara suatu produk dengan produk lainnya dan untuk mempromosikan produk ke wilayah yang lebih luas.

Iklan merupakan cara agar sebuah produk dapat dikenal oleh khalayak sehingga dapat memberikan pengaruh terhadap dikenalnya suatu produk yang berimbas kepada penjualan. Pemasar perlu memperhatikan deskripsi tentang produk/jasa yang mereka jual agar iklan tersebut sampai pada pikiran konsumen. Saat ini periklanan secara tidak langsung dapat membuat pikiran orang menjadi ingat atau sadar terhadap suatu produk. (Wicaksono \& Seminari, 2016)

Periklanan adalah jenis komunikasi pemasaran yang merupakan istilah umum yang mengacu kepada semua bentuk teknik komunikasi yang digunakan pemasar untuk menjangkau konsumennya dan menyampaikan pesannya. Cara-cara itu dapat berupa promosi penjualan sampai pemasaran langsung acara sponsor, pengemasan, dan penjualan personal.

Adapun fungsi iklan yakni; (a) Informing (memberi infomasi), (b) Persuading (mempersuasi) (c) Reminding (mengingatkan) (d) Adding value (memberikan nilai tambah). (e) Assisting (mendampingi). Tujuan periklanan adalah tujuan yang diupayakan untuk dicapai oleh periklanan. Penyusunan tujuan periklanan yang baik merupakan tugas sulit dari manajemen periklanan namun tujuan-tujuan tersebut menjadi pondasi bagi seluruh keputusan periklanan yang ditetapkan.

Tujuan suatu iklan merupakan bentuk komunikasi yang spesifik untuk meraih khalayak yang khusus sepanjang periode waktu tertentu. Dalam perspektif Islam, periklanan yang Islami diartikan sebagai proses penyampaian pesan komersial maupun layanan masyarakat yang disampaikan berdasarkan kaidah Islam. Kaidah Islam berarti bersumber pada Al-Qur'an dan Al-Hadist. Kedua pasangan hidup dalam masyarakat yang beragama Islam ini bersifat dinamis, teks (nash) tidak akan bermakna apapun jika tidak diletakkan dalam konteksnya (Muhammad \& Alimin, 2005). Banyak teks yang secara nyata mengatur etika dalam berkomunikasi, sejumlah ayat suci Al-Quran mengkaitkan cara berkomunikasi yang baik.

Perlunya etika periklanan juga muncul dari keinginan untuk melindungi konsumen. Sebab dewasa ini banyak produk dihasilkan namun tidak cocok untuk konsumen itu sendiri. Fakta di lapangan telah banyak kasus dimana konsumen menderita kerugian karena menggunakan produk. 
Iklan yang jujur tidak menjerumuskan dan tidak mendatangkan kerugian konsumen sangat dibutuhkan. Iklan semacam ini akan meningkatkan kepercayaan masyarakat pada pesan iklan itu sendiri. Sebaliknya bila iklan tidak jujur, menjerumuskan dan merugikan maka akan meruntuhkan kepercayaan konsumen terhadap pesan iklan. Kepercayaan khalayak terhadap iklan pada gilirannya akan meningkatkan kepercayaan terhadap pembuat iklan tersebut, maka kredibilitas profesi pembuat iklan akan meningkat pula. (Rangkuti, 2008)

Dalam praktik dagang sederhana (skala kecil), untuk melariskan barang dagangnya, seorang pedagang kadangkala tidak segan-segan bersumpah. Sangat banyak ayat AL-Qur'an yang menyinggung tentang penyampaian informasi yang tidak benar pada orang lain, di antaranya ayat 77 , surah 'Ali-Imran tentang pelarangan promosi yang tidak sesuai dengan kualifikasi barang : yang Artinya : sesungguhnya orang-orang yang menukar janji (nya dengan) Allah dan sumpah-sumpah mereka dengan harga yang sedikit, mereka itu tidak mendapatkan bahagian (pahala) diakhirat, dan Allah tidak akan berkata-kata dengan mereka dan tidak akan melihat kepada mereka pada hari kiamat dan tidak (pula) akan mensucikan mereka. Bagi mereka azab yang pedih.

\section{Keputusan Pembelian}

Keputusan pembelian merupakan salah satu komponen utama dari perilaku konsumen. Suatu keputusan melibatkan pilihan diantara dua atau lebih alternative tindakan. Pengertian mengenai perilaku konsumen oleh perusahaan selaku produsen begitu penting dan perlu diperhatikan lebih lanjut. Dalam memahami perilaku konsumen terdapat banyak pengaruh yang mendasari seseorang dalam mengambil keputusan pembelian suatu produk dan merek. Pada kebanyakan orang perilaku pembelian konsumen seringkali diawali dan di pengaruhi oleh banyaknya rangsangan dari luar dirinya, baik berupa rangsangan pemasaran maupun rangsangan dari lingkungan yang lain. Rangsangan tersebut kemudian diproses dalam diri sesuai dengan karakteristik pribadinya sebelum akhirnya diambil keputusan pembelian. (Supranto \& Nandan, 2011)

Keputusan membeli suatu produk ada pada diri konsumen karena pasar menyediakan berbagai pilihan produk dan merek yang beragam. Konsumen bebas memilih berbagai produk dengan menggunakan berbagai kriteria yang sesuai dengan 
kebutuhan. Para pemasar yang memahami keinginan konsumen memilih suatu produk, memungkinkannya mempengaruhi keputusan pembelian dan memiliki kemampuan yang lebih baik untuk mempengaruhi keputusan pembelian dan memiliki kemampuan yang lebih baik untuk memenangkan kompetisi pasar. (Usvita, 2013)

Faktor-Faktor Keputusan Pembelian adalah: (a) Faktor Psikologis mencakup persepsi, motivasi, pembelajaran, sikap, dan keperibadian. (b) Faktor situasional mencakup keadaan saran dan prasarana, tempat belanja, waktu berbelanja, penggunaan produk dan kondisi saat pembelian. (c) Faktor sosial mencakup undang-undang atau peraturan keluarga, kelompok referensi, kelas sosial, dan budaya.

Menurut Kertamukti (2013) ada faktor-faktor utama lainnya yang menjadi keputusan pembelian konsumen adalah: (a) Faktor Kebudayaan (b) Faktor Sosial. (c) Faktor Pribadi. (d) Faktor Psikologis .

\section{Proses Pengambilan Keputusan}

Proses pembelian yang spesifik terdiri dai urutan kejadian berikut: pengenalan masalah, pencarian informasi, evaluasi alternatif, keputusan pembelian, dan perilaku pasca-pembelian.

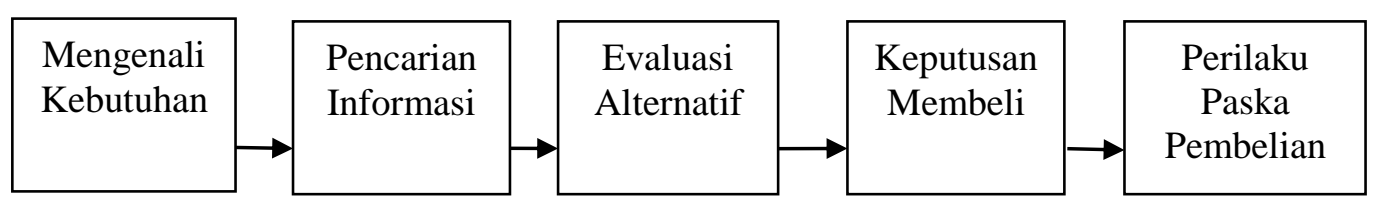

Gambar 1 Proses Pembelian

Sumber : Setiadi (2013)

Proses pembelian pengambilan keputusan sebagai aktivitas penting dalam perilaku konsumen harus dipahami untuk merumuskan strategi pemasaran yang tepat yang mampu mempengaruhi setiap tahapan proses pengambilan keputusan yang berlangsung.

\section{Pengaruh Iklan Islami pada Sikap Konsumen}

Pengaruh iklan pada perilaku konsumen ini sangat variatif, mulai dari mendorong konsumen untuk mencari produk yang di maksud sampai dengan mendorong orang yang sebelumnya loyal menjadi tidak loyal. Untuk menghasilkan 
iklan yang efektif sekaligus bisa membius public, tentunya dibutuhkan strategi perancangan yang matang. Bukan cuman tampilan fisik tapi juga mampu mengomunikasikan pesan yang tersembunyi. Artinya, mampu memadukan pesan yang eksplisit dengan pesan yang implisit. Disinilah, dibutuhkan strategi cerdas dan bijak agar pesan yang dikedepankan bisa ditangkap dalam durasi waktu tertentu, untuk strata sosial dan usia yang bervariasi (Kertamukti, 2013)

Djakfar (2012) menyebutkan bahwa Pengaruh iklan pada sikap konsumen terhadap produk antara lain : (a) Berbisnis bukan hanya mencari keuntungan, tetapi itu harus diniatkan sebagai ibadah kita kepada Allah SWT. (b) Sikap jujur. (3) Sikap toleransi antar penjual dan pembeli. (4) Tekun dalam menjalankan usaha. (5) Berlaku adil dam melakukan persaingan sesama pebisnis dengan baik dan, (6) sehat.

\section{METODE PENELITIAN}

Jenis penelitian ini adalah penelitian kausalitas. Kausalitas adalah jenis penelitian yang disusun untuk meneliti kemungkinan adanya hubungan sebab akibat antara variabel.

Populasi dalam penelitian ini adalah seluruh Mahasiswi yang menggunakan Shampoo Sunsilk Hijab Clean and Fresh pada dua fakultas yang berada di Universitas Islam Riau yaitu Fakultas Agama Islam pada program studi Ekonomi Syariah dan Fakultas Ekonomi pada program studi Ekonomi Pembangunan, Manajemen dan Akuntansi yang berjumlah 2.575 mahasiswi.

Sampel adalah proses memilih sejumlah elemen secukupnya dari populasi, sehingga penelitian terhadap sampelnya dan pemahaman tentang sifat atau karakteristiknya akan membuat kita dapat menggeneralisasikan sifat atau karakteristik tersebut pada elemen populasi. (Sekaran, 2007). Berikut ini adalah cara menentukan jumlah elemen atau anggota sampel dari suatu populasi dengan menggunakan rumus Slovin :

$$
\mathrm{n}=\frac{N}{1+N \mathrm{e}^{2}}
$$

keterangan :

$$
\begin{aligned}
& \mathrm{n}=\text { ukuran sampel } \\
& \mathrm{N}=\text { ukuran populasi }
\end{aligned}
$$


$\alpha=$ toleransi ketidak telitian (dalam persen)

Dalam penelitian ini jumlah populasi $(\mathrm{N})=2.580$ orang dengan nilai kritis

(e) sebesar $10 \%$ maka ukuran sampel:

$$
\begin{aligned}
\mathrm{n} & =\frac{2.580}{1+(2.580)(10 \%)^{2}} \\
& =96,26 \text { konsumen }
\end{aligned}
$$

Jadi dalam penelitian ini ukuran sampelnya dibulatkan sebanyak 96 konsumen. Dan teknik pengambilan sampel dalam penelitian ini adalah menggunakan sampel random sampling. Dari jumlah sampel tersebut dapat di tentukan jumlah masing-masing sampel menurut tingkat (strata) dengan teknik penganbilan sampel menggunakan Proportionate Stratified Random Sampling, dengan rumus (Riduwan, 2008):

$$
\mathrm{Ni}=\mathrm{Ni} / \mathrm{N} . \mathrm{n}
$$

1. Ekonomi Syariah

$$
147 / 2.580 \times 96=6
$$

2. Perbankan Syariah

$$
5 / 2.580 \times 96=1
$$

3. Ekonomi Pembangunan

$142 / 2.580 \times 96=5$

4. Manajemen

$$
1.108 / 2.580 \times 96=41
$$

5. Akuntansi

$$
1.178 / 2.580 \times 96=43
$$

Penelitian ini juga menggunakan analisis data dengan Uji Validitas dan Realibilitas, sedangkan

\section{HASIL PENELITIAN}

\section{Uji Validitas \& Realibilitas}

Uji validitas yaitu uji dengan menggunakan rumus Corrected Item dengan taraf signifikan sebesar 5\% $(\alpha=0,05)$ artinya suatu item dianggap valid jika berkorelasi signifikan terhadap skor total. 
Dari hasil penelitian terhadap indikator setiap variabel dalam penelitian ini semuanya valid. Indikator setiap variabel signifikan terhadap topik yang diteliti. Berikut hasil pengujian validitas untuk item-item Pengaruh Periklanan Islami terhadap Keputusan Pembelian Shampoo Hijab Sunsilk Clean and Fresh pada Mahasiswi Universitas Islam Riau. Tabel tentang hasil uji validitas dan butir-butir pernyataan responden penelitian:

\begin{tabular}{|c|c|c|c|c|}
\hline \multicolumn{5}{|c|}{$\begin{array}{c}\text { Tabel } 2 \\
\text { Hasil Uji Validitas }\end{array}$} \\
\hline variabel & $\begin{array}{c}\text { Item } \\
\text { pernyataan }\end{array}$ & $\begin{array}{c}\text { Corrected Item-Total } \\
\text { Correlation }\end{array}$ & $\begin{array}{c}\mathrm{R} \text { tabel } \\
\mathrm{A}=0,05\end{array}$ & $\begin{array}{c}\text { Keterangan } \\
\text { valid }\end{array}$ \\
\hline $\mathrm{X}$ & $\begin{array}{l}\text { Item } 1 \\
\text { Item } 2 \\
\text { Item } 3 \\
\text { Item } 4 \\
\text { Item } 5 \\
\text { Item } 6 \\
\text { Item } 7 \\
\text { Item } 8 \\
\text { Item } 9 \\
\text { Item } 10 \\
\text { Item } 11 \\
\text { Item } 12 \\
\text { Item } 13 \\
\text { Item } 14 \\
\text { Item } 15 \\
\text { Item } 16 \\
\text { Item } 17 \\
\text { Item } 18\end{array}$ & $\begin{array}{l}0,725 \\
0,690 \\
0,593 \\
0,545 \\
0,479 \\
0,501 \\
0,530 \\
0,545 \\
0,563 \\
0,618 \\
0,564 \\
0,575 \\
0,753 \\
0,687 \\
0,608 \\
0,540 \\
0,720 \\
0,776\end{array}$ & $\begin{array}{l}0,168 \\
0,168 \\
0,168 \\
0,168 \\
0,168 \\
0,168 \\
0,168 \\
0,168 \\
0,168 \\
0,168 \\
0,168 \\
0,168 \\
0,168 \\
0,168 \\
0,168 \\
0,168 \\
0,168 \\
0,168\end{array}$ & $\begin{array}{l}\text { Valid } \\
\text { Valid } \\
\text { Valid } \\
\text { Valid } \\
\text { Valid } \\
\text { Valid } \\
\text { Valid } \\
\text { Valid } \\
\text { Valid } \\
\text { Valid } \\
\text { Valid } \\
\text { Valid } \\
\text { Valid } \\
\text { Valid } \\
\text { Valid } \\
\text { Valid } \\
\text { Valid } \\
\text { Valid }\end{array}$ \\
\hline $\mathrm{Y}$ & $\begin{array}{l}\text { Item } 19 \\
\text { Item } 20 \\
\text { Item } 21 \\
\text { Item } 22 \\
\text { Item } 23 \\
\text { Item } 24 \\
\text { Item } 25 \\
\text { Item } 26 \\
\text { Item } 27 \\
\text { Item } 28 \\
\text { Item } 29 \\
\text { Item } 30\end{array}$ & $\begin{array}{l}0,669 \\
0,527 \\
0,501 \\
0,603 \\
0,493 \\
0,600 \\
0,656 \\
0,659 \\
0,667 \\
0,636 \\
0,652 \\
0,731\end{array}$ & $\begin{array}{l}0,168 \\
0,168 \\
0,168 \\
0,168 \\
0,168 \\
0,168 \\
0,168 \\
0,168 \\
0,168 \\
0,168 \\
0,168 \\
0,168\end{array}$ & $\begin{array}{l}\text { Valid } \\
\text { Valid } \\
\text { Valid } \\
\text { Valid } \\
\text { Valid } \\
\text { Valid } \\
\text { Valid } \\
\text { Valid } \\
\text { Valid } \\
\text { Valid } \\
\text { Valid } \\
\text { Valid }\end{array}$ \\
\hline
\end{tabular}

Sumber: Data Olahan SPSS Versi 23, 2017

Dari tabel diatas dapat disimpulkan bahwa indikator variabel dapat dikatakan valid karena, jika $r_{\text {hitung }}>r_{\text {tabel }}$ maka item-item pernyataan dinyatakan valid. Diketahui nilai rtabel dengan taraf signifikan 5\% $(\alpha=0,05)$ adalah sebesar 0,168 (lihat tabel $r$ ) dan nilai dibandingkan dengan nilai rhitung. Nilai rhitung dalam uji validitas ini adalah pada 
kolom Item- Total Statistic (Corrected Item- Total). Dan dari tabel diatas menunjukkan bahwa butir pernyataan tersebut dinyatakan valid.

Uji Reliabilitas, batasan nilai dalam uji reliabilitas adalah 0,6. Jika nilai reliabilitas kurang dari 0,6 maka nilainya kurang baik. Nilai reliabilitas dalam uji ini adalah kolom Reliability Statistic (Cronbach's Alpha). Tabel tentang hasil uji validitas dari butir-butir pernyataan responden penelitian.

Tabel 3

Hasil Uji Reliabilitas

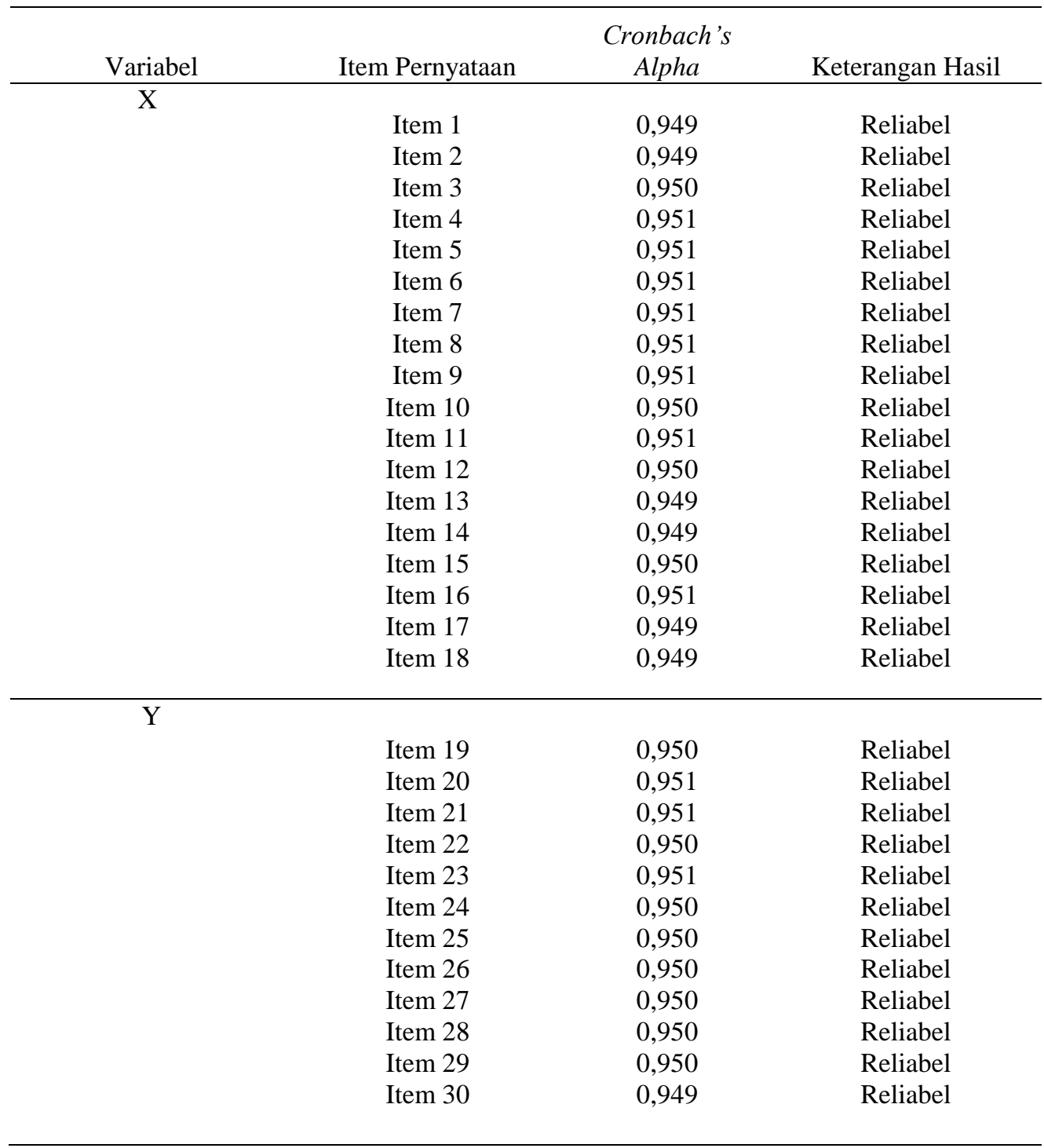

Sumber: Data Olahan SPSS Versi 23, 2017 
Berdasarkan uji reliabilitas dengan menggunakan Cronbach's Alpha diatas dapat disimpulkan bahwa 30 butir pernyataan tentang Pengaruh Periklanan Islami terhadap Keputusan Pembelian Shampoo Sunsilk Hijab Clean And Fresh pada Mahasiswi Universitas Islam Riau dapat dinyatakan reliabel.

\section{Analisis Regresi Sederhana}

Hasil perhitungan analisis regresi sederhana melalui SPSS For Windows Versi 23, maka di peroleh nilai-nilai untuk variabel bebas dan variabel terikat dapat dilihat pada tabel:

Tabel 4

Hasil Uji Analisis Regresi Sederhana

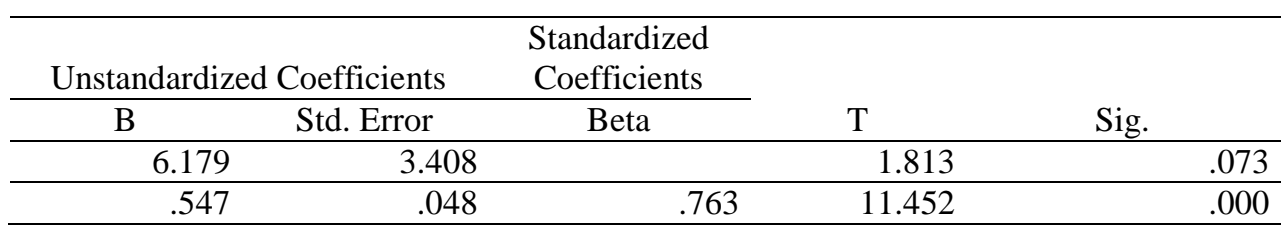

Sumber: Data Olahan SPSS Versi 23

Bentuk umum dari persamaan regresi dinyatakan dengan persamaan matematika, yaitu:

$$
\begin{aligned}
& \hat{Y}=a+b X \\
& \hat{Y}=6.179+0,547 X
\end{aligned}
$$

Arti angka-angka dalam persamaan regresi di atas adalah: (1) Nilai a $=6.179$. menunjukkan bahwa apabila nilai $X=0$, maka nilai variabel Y sebesar 6.179. (2) Nilai $\mathrm{b}=0,547$ menunjukkan bahwa apabila nilai variabel periklanan Islami $(\mathrm{X})$ meningkat maka variabel keputusan pembelian (Y) akan mengalami peningkatan sebesar 0,547 satuan dengan asumsi variabel $\mathrm{X}$ tetap atau konsisten.

\section{Uji -t (Uji Parsial)}

Uji-t dilakukan untuk melihat pengaruh masing-masing variabel, yaitu variabel bebas dan variabel terikat dengan menggunakan Uji-t (Uji Parsial) dengan menggunakan bantuan komputer program SPSS For Windows Versi 23, maka Uji-t dapat dilihat pada tabel berikut: 
Tabel 5

Hasil Perhitungan Uji-t

\begin{tabular}{llllll}
\hline & \multicolumn{2}{l}{$\begin{array}{l}\text { Unstandardized } \\
\text { Coefficients }\end{array}$} & \multicolumn{2}{l}{$\begin{array}{l}\text { Standardized } \\
\text { Coefficients }\end{array}$} & \\
\cline { 2 - 5 } Model & $\mathrm{B}$ & Std. Error & Beta & T & Sig. \\
\hline (Constant) & 6.179 & 3.408 & & 1.813 & .073 \\
\hline Periklanan Islami & .547 & .048 & .763 & 11.452 & .000 \\
\hline Sumber: Data Olahan SPSS Versi 23 & & & &
\end{tabular}

Dari pengelolaan tabel di atas dapat diketahui bahwa nilai t hitung variabel periklanan Islami $(\mathrm{X})$ sebesar 11.452 dan nilai t tabel di dapat dari $\mathrm{dk}=\mathrm{n}-2$, maka $\mathrm{dk}=96-2=94$. Dengan taraf signifikan sebesar $0.05(5 \%)$ maka t tabel adalah 1,661, maka terlihat bahwa $t_{\text {hitung }}>t_{\text {tabel }}$ atau $11.452>1,661$, maka ha diterima dan ho ditolak, sehingga dapat dikatakan terdapat pengaruh yang signifikan antara periklanan Islami terhadap Keputusan Pembelian Shampoo Hijab Sunsilk Clean and Fresh pada Mahasiswi Universitas Islam Riau.

\section{Koefisien Korelasi}

Koefisien korelasi berfungsi untuk melihat kuat lemahnya pengaruh antara variabel bebas terhadap variabel terikat. Untuk mengetahui hal tersebut, maka dapat digunakan koefisien korelasi dengan menggunakan bantuan computer program SPSS for Windows Versi 23, dan hasilnya dapat dilihat pada tabel berikut:

Tabel 6 Analisis Korelasi

\begin{tabular}{lllll}
\hline Model & R & R Square & Adjusted R Square & $\begin{array}{l}\text { Std. Estimate } \\
\text { Error of }\end{array}$ \\
\hline 1 & $.763^{\text {a }}$ & .582 & .578 & 4.553 \\
\hline Sumber: Data & Olahan SPSS Versi 23 & & \\
\hline
\end{tabular}

Dari pengelolaan tabel diatas dapat diketahui bahwa nilai $\mathrm{R}$ menunjukkan korelasi antara variabel independen dengan variabel dependen. Diketahui nilai $\mathrm{R}$ sebesar 0,763 Berdasarkan tabel interval koefisien dengan tingkat hubungan, maka KK berada pada pada $0.60<\mathrm{KK}<0,799$, yang berarti interpretasi koefisien korelasinya kuat atau tinggi. 


\section{Koefisien Determinasi}

Sedangkan untuk melihat besarnya kontribusi variabel X terhadap Y dilihat dari koefisien determinasi. Koefisien Determinasi (R) adalah menunjukkan seberapa besar perubahan variabel terikat (Y) yang dapat dipengaruhi oleh variabel bebas (X). Diketahui nilai $\mathrm{R}$ square sebesar 58,2\%, artinya variabel $\mathrm{X}$ (periklanan islami) memiliki kontribusi sebesar 58,2\% terhadap variabel Y (keputusan pembelian) dan 41,8\% lainnya di pengaruhi oleh faktor-faktor lain diluar variabel X.

\section{PEMBAHASAN}

Hasil penelitian menunjukkan adanya pengaruh Periklanan Islami Terhadap Keputusan Pembelian Produk Shampoo Hijab Sunsilk Clean And Fresh Pada Mahasiswi Universitas Islam Riau. Periklanan islami dimaksudkan adalah sebuah strategi periklanan yang dilakukan oleh perusahaan sesuai dengan syariat islam. Perlunya etika periklanan juga muncul dari keinginan untuk melindungi konsumen. Sebab dewasa ini banyak produk dihasilkan namun tidak cocok untuk konsumen itu sendiri. Fakta di lapangan telah banyak kasus dimana konsumen menderita kerugian karena menggunakan produk. Iklan yang jujur tidak menjerumuskan dan tidak mendatangkan kerugian konsumen sangat dibutuhkan. Iklan semacam ini akan meningkatkan kepercayaan masyarakat pada pesan iklan itu sendiri. Sebaliknya bila iklan tidak jujur, menjerumuskan dan merugikan maka akan meruntuhkan kepercayaan konsumen terhadap pesan iklan. Kepercayaan khalayak terhadap iklan pada gilirannya akan meningkatkan kepercayaan terhadap pembuat iklan tersebut, maka kredibilitas profesi pembuat iklan akan meningkat pula. (Rangkuti, 2008).

Pengaruh iklan pada perilaku konsumen ini sangat variatif, mulai dari mendorong konsumen untuk mencari produk yang di maksud sampai dengan mendorong orang yang sebelumnya loyal menjadi tidak loyal. Untuk menghasilkan iklan yang efektif sekaligus bisa membius public, tentunya dibutuhkan strategi perancangan yang matang. Bukan cuman tampilan fisik tapi juga mampu mengomunikasikan pesan yang tersembunyi. Artinya, mampu memadukan pesan yang eksplisit dengan pesan yang implisit. Disinilah, dibutuhkan strategi cerdas dan bijak agar pesan yang dikedepankan bisa ditangkap dalam durasi waktu tertentu, untuk strata sosial dan usia yang bervariasi. (Kertamukti, 2013). 


\section{SIMPULAN}

Berdasarkan dari hasil pembahasan yang telah diuraikan pada bab-bab sebelumnya yang membahas pengaruh periklanan Islami terhadap keputusan pembelian Shampoo Hijab Sunsilk Clean and Fresh pada Mahasiswi Universitas Islam Riau, maka penulis dapat menyusun beberapa kesimpulan sebagai berikut: (a) Dari hasil uji parsial diketahui bahwa terdapat pengaruh yang signifikan antara periklanan Islami terhadap keputusan pembelian Shampoo Hijab Sunsilk Clean and Fresh pada Mahasiswi Universitas Islam Riau. (b) Adapun hasil koefisien korelasi menyatakan adanya hubungan yang kuat atau tinggi antara periklanan Islami terhadap keputusan pembelian Shampoo Hijab Sunsilk Clean and Fresh. (c) Sedangkan hasil koefisien determinasi menunjukkan terdapat kontribusi yang kuat antara periklanan Islami terhadap keputusan pembelian Shampoo Hijab Sunsilk Clean and Fresh.

\section{DAFTAR RUJUKAN}

Al-Qur'an dan Terjemahannya. (2005). Bandung: PT. Syaamil Cipta Media

Al-Hadist. (2011). Ayat-Ayat dan Hadist Ekonomi Syariah. Jakarta: PT Raja Grafindo Persada

Djakfar, Muhammad. (2012). Etika Bisnis. Jakarta: Penebar Swadaya

Kertamukti, Rama. (2013). Strategi Kreatif dalam Periklanan. Jakarta: PT Rajagrafindo Persada

Muhammad \& Alimin. (2005). Etika Perlindungan Konsumen dalam Ekonomi Islam. Yogyakarta.

Rangkuti, Freddy. (2008). Creating Effective Marketing Plan. Jakarta: Gramedia Pustaka Utama

Setiadi, J Nugroho. (2013). Perilaku Konsumen. Yogyakarta: CV. Andi Offeset

Supranto \& Nandan, Limakrisna. (2011). Perilaku Konsumen dan Strategi Pemasaran. Jakarta: Mitra Wacana Media

Sekaran, Uma. (2007). Metodologi Penelitian untuk Bisnis. Jakarta: PT Salemba Empat

Usvita, Mega. (2013). Pengaruh Iklan dan Sikap Konsumen terhadap Keputusan Pembelian Cream Wajah Pond's Pada Mahasiswi Sekolah Tinggi Ilmu Ekonomi Yayasan Pendidikan Pasaman (Stie Yappas), e-Jurnal Apresiasi Ekonomi. 1 (1): 46-56

Wicaksono, M,P,A \& Seminari, N,K. (2016). Pengaruh Iklan dan Word Of Mouth Terhadap Brand Awareness Traveloka, E- Jurnal Manajemen Unud, 5 (1): 67-77 